\title{
Red blood cell distribution width predicts mortality after coronary artery bypass grafting
}

\author{
Umberto Benedetto ${ }^{\mathrm{a}, *, 1}$, Emiliano Angeloni ${ }^{\mathrm{a}, 1}$, Giovanni Melina ${ }^{\mathrm{a}, 1}$, Calogera Pisano ${ }^{\mathrm{b}, 1}$, Andrea Lechiancole ${ }^{\mathrm{a}, 1}$, \\ Antonino Roscitano ${ }^{\mathrm{a}, 1}$, Martin Pooley ${ }^{\mathrm{b}, 1}$, Cosimo Comito ${ }^{\mathrm{a}, 1}$, Massimiliano Codispoti ${ }^{\mathrm{b}, 1}$, Riccardo Sinatra ${ }^{\mathrm{a}, 1}$ \\ a Department of Cardiac Surgery, Ospedale Sant'Andrea, Sapienza University of Rome, Italy \\ b Department of Cardiac Surgery, Papworth Hospital NHS, United Kingdom
}

\section{A R T I C L E I N F O}

\section{Article history:}

Received 26 June 2012

Accepted 23 August 2012

Available online 7 September 2012

\section{Keywords:}

Anaemia

CABG

Mortality

Risk stratification in cardiac surgery is a relevant issue. Many mortality risk models are currently available [1,2], and they are used to assess risk of operative mortality, and to provide internal and/or external benchmark comparisons. However these risk models, such as the European System for Cardiac Operative Risk Evaluation (EuroSCORE) [2], have shown several limitations, including poor performance in the elderly and overestimated mortality, especially among isolated coronary artery bypass grafting (CABG) patients. Therefore there is a need to identify new risk factors in this setting which are expected to be simple enough for clinical use, available for all patients and cost-effective.

Complete blood cell count parameters, such as haemoglobin, have been shown to predict outcomes in patients with cardiovascular disease $[3,4]$ but none of them has been incorporated into surgical risk scores. In particular, the preoperative haemoglobin has been investigated as a risk factor of early death but discordant results were reported.

Red blood cell distribution width (RDW), routinely reported in automated complete blood counts, is a numerical measure of the variability in size of circulating erythrocytes, and has been emerging as a strong predictor of adverse events for several categories of patients [5]. However, the role of RDW in predicting mortality of CABG patients has not been investigated yet.

To assess predictive power of RDW on both early and late mortalities following CABG, prospectively collected data from the surgical database of two European institutions (Sapienza University of Rome, Italy and Papworth Hospital NHS, United Kingdom) have been retrospectively analysed by authors whom have certified that they comply with the Principles of Ethical Publishing in the International Journal of Cardiology.

The primary end points of the study were early (within 30 day) death and all-cause late death after hospital discharge. All-cause death is the most robust and unbiased index because no adjudication is required, thus avoiding inaccurate or biased documentation and clinical assessments. Furthermore, to deeply investigate the relationship between RDW and mortality, cause of deaths were recorded and a sub-analysis of cardiac-related late mortality was performed (any

\footnotetext{
* Corresponding author at: Division of Cardiac Surgery, Sapienza University of Rome, Via di Grottarossa 1035, 00139 Rome, Italy. Tel.: + 39 0633775593; fax: + 39 0633775483.

E-mail address: u2benedetto@libero.it (U. Benedetto).

1 This author takes responsibility for all aspects of the reliability and freedom from bias of the data presented and their discussed interpretation.
}

sudden, cardiac, or unknown death was considered a cardiac-related death; stroke as well was considered as cardiac death).

Participants were classified into 4 groups using the RDW quartile values. Differences in baseline clinical characteristics among groups were examined by 1-way analysis of variance for continuous variables and $\chi^{2}$ test for categorical variables. Kaplan-Meier analysis of survival was performed and estimates were compared with logrank test.

Potential confounding factors were derived among variables included into EuroSCORE [1,2], on the basis of a literature review and a clinical plausibility. We used 4 stepwise logistic and Cox proportional hazards models to assess the associations between the baseline RDW quartiles and risks of early and late mortalities. Estimates were calculated as crude association between outcomes and RDW quartiles (Model 1), adjusting for demographic risk factors showing significant correlation at univariate analysis (Model 2), adding haemoglobin levels (Model 3), and adding other biochemical factors (Model 4). All statistical analyses were performed using SPSS v. 20.0 (SPSS, Chicago, IL).

Table 1

Baseline clinical characteristics stratified for baseline quartiles of red blood cell distribution width (RDW).

\begin{tabular}{|c|c|c|c|c|c|}
\hline \multirow[t]{2}{*}{ Characteristics } & \multicolumn{5}{|c|}{ RDW quartile } \\
\hline & $\begin{array}{l}\leq 12.9 \\
(\mathrm{n}= \\
2208)\end{array}$ & $\begin{array}{l}12.9-13.4 \\
(\mathrm{n}= \\
2134)\end{array}$ & $\begin{array}{l}13.4-14.0 \\
(\mathrm{n}= \\
1932)\end{array}$ & $\begin{array}{l}>14.0 \\
(\mathrm{n}= \\
2066)\end{array}$ & P value \\
\hline Age (years) & $63 \pm 12$ & $66 \pm 13$ & $68 \pm 12$ & $69 \pm 13$ & $<0.0001$ \\
\hline Women, \% & 13 & 15 & 22 & 30 & $<0.0001$ \\
\hline BMI, \% & & & & & 0.3 \\
\hline$<18.5 \mathrm{~kg} / \mathrm{m}^{2}$ & 1 & 2 & 1 & 1 & \\
\hline $\begin{array}{l}18.5 \mathrm{~kg} / \mathrm{m}^{2} \text { to } \\
25 \mathrm{~kg} / \mathrm{m}^{2}\end{array}$ & 25.5 & 28 & 25 & 25 & \\
\hline 25 to $29.9 \mathrm{~kg} / \mathrm{m}^{2}$ & 49 & 46 & 49 & 50 & \\
\hline$>30 \mathrm{~kg} / \mathrm{m}^{2}$ & 24.5 & 24 & 24 & 24 & \\
\hline $\begin{array}{l}\text { Glomerular filtration rate } \\
(\mathrm{mL} / \mathrm{min})\end{array}$ & $81 \pm 5$ & $79 \pm 8$ & $77 \pm 5$ & $59 \pm 7$ & $<0.001$ \\
\hline Extracardiac arteriopathy, \% & 24 & 26 & 25 & 28 & 0.16 \\
\hline Previous cardiac surgery, \% & 3 & 2 & 2 & 3 & 0.63 \\
\hline Chronic lung disease, \% & 15 & 21 & 22 & 17 & 0.52 \\
\hline $\begin{array}{l}\text { Critical preoperative } \\
\text { state, \% }\end{array}$ & 5 & 4 & 5 & 5 & 0.41 \\
\hline Diabetes on insulin, \% & $86(27 \%)$ & $76(23 \%)$ & $103(28 \%)$ & $109(33 \%)$ & 0.006 \\
\hline Preoperative NHYA III/IV, \% & 11 & 12 & 9 & 13 & 0.47 \\
\hline LV function, $\%$ & & & & & 0.19 \\
\hline Good $(\geq 50 \%)$ & 31 & 33 & 39 & 35 & \\
\hline Moderate (31-49\%) & 45 & 38 & 41 & 41 & \\
\hline Poor $(\leq 30 \%)$ & 24 & 29 & 20 & 24 & \\
\hline MI within 90 days, \% & 26 & 28 & 23 & 21 & 0.32 \\
\hline Pulmonary hypertension, \% & 16 & 15 & 18 & 10 & 0.68 \\
\hline Emergent/urgent indication, \% & 8 & 5 & 5 & 7 & 0.21 \\
\hline $\begin{array}{l}\text { Baseline haemoglobin } \\
(\mathrm{g} / \mathrm{dL})\end{array}$ & $13.6 \pm 1.4$ & $13.4 \pm 1.5$ & $13.4 \pm 1.6$ & $12.3 \pm 1.8$ & $<0.0001$ \\
\hline $\operatorname{MCV}\left(\mu \mathrm{m}^{3}\right)$ & $88 \pm 4$ & $88 \pm 4$ & $87 \pm 5$ & $81 \pm 5$ & $<0.0001$ \\
\hline Serum iron $(\mu \mathrm{g} / \mathrm{dL})$ & $88 \pm 37$ & $91 \pm 35$ & $85 \pm 31$ & $89 \pm 28$ & 0.26 \\
\hline Serum vitamin $B_{12}(\mathrm{pg} / \mathrm{mL})$ & $\begin{array}{l}901 \\
\pm 116\end{array}$ & $\begin{array}{l}731 \\
\pm 279\end{array}$ & $672 \pm 211$ & $722 \pm 187$ & 0.69 \\
\hline Serum folic acid (ng/mL) & $\overline{14.1} \pm 7.2$ & $13.8 \pm 3.1$ & $13.7 \pm 6.1$ & $14.5 \pm 2.1$ & 0.55 \\
\hline C-reactive protein $(\mathrm{mg} / \mathrm{L})$ & $14.3 \pm 2.1$ & $14.8 \pm 3.1$ & $17.1 \pm 3.7$ & $22.1 \pm 4.1$ & 0.001 \\
\hline
\end{tabular}

BMI: body mass index; NYHA: New York Heart Association; LV: left ventricular; MI: myocardial infarction; MCV: mean corpuscular volume. 
Table 2

Association between quartiles of baseline red blood cell distribution width (RDW) and early and late mortalities.

\begin{tabular}{|c|c|c|c|c|}
\hline $\begin{array}{l}\text { Mortality and RDW } \\
\text { quartiles }\end{array}$ & Model 1 & Model 2* & Model 3 & Model 4 \\
\hline Early mortality & $\overline{\mathrm{OR}}(95 \% \mathrm{CI})$ & $\overline{\mathrm{OR}}(95 \% \mathrm{CI})$ & $\overline{\mathrm{OR}(95 \% \mathrm{CI})}$ & $\overline{\mathrm{OR}(95 \% \mathrm{CI})}$ \\
\hline$\overline{1(<12.9)}$ & 1.00 & 1.00 & 1.00 & 1.00 \\
\hline $2(12.9-13.4)$ & $\begin{array}{l}1.23(0.99- \\
2.76)\end{array}$ & $\begin{array}{l}1.41(0.99- \\
3.14)\end{array}$ & $\begin{array}{l}1.09(0.79- \\
2.84)\end{array}$ & $\begin{array}{l}1.05(0.79- \\
3.76)\end{array}$ \\
\hline $3(13.4-14.0)$ & $\begin{array}{l}1.71(1.11- \\
3.67)\end{array}$ & $\begin{array}{l}1.53(1.13- \\
3.79)\end{array}$ & $\begin{array}{l}1.44(1.01- \\
2.99)\end{array}$ & $\begin{array}{l}1.31(1.001- \\
4.32)\end{array}$ \\
\hline $4(>14)$ & $\begin{array}{l}3.21(2.73- \\
4.14)\end{array}$ & $\begin{array}{l}3.01(1.98- \\
4.23)\end{array}$ & $\begin{array}{l}2.99(1.45- \\
4.01)\end{array}$ & $\begin{array}{l}2.43(1.18- \\
5.01)\end{array}$ \\
\hline P for trend & $<0.001$ & $<0.001$ & 0.005 & 0.009 \\
\hline Late mortality & HR $(95 \% \mathrm{CI})$ & $\mathrm{HR}(95 \% \mathrm{CI})$ & HR $(95 \% \mathrm{CI})$ & HR $(95 \% \mathrm{CI})$ \\
\hline$\overline{1(<12.9)}$ & $\overline{1.00}$ & 1.00 & 1.00 & 1.00 \\
\hline $2(12.9-13.4)$ & $\begin{array}{l}1.47(1.09- \\
3.78)\end{array}$ & $\begin{array}{l}1.39(1.05- \\
3.63)\end{array}$ & $\begin{array}{l}1.29(1.01- \\
3.50)\end{array}$ & $\begin{array}{l}1.22(0.91- \\
3.99)\end{array}$ \\
\hline $3(13.4-14.0)$ & $\begin{array}{l}2.47(1.31- \\
4.23)\end{array}$ & $\begin{array}{l}2.41(1.18- \\
3.45)\end{array}$ & $\begin{array}{l}2.18(1.08- \\
3.36)\end{array}$ & $\begin{array}{l}2.35(1.08- \\
4.36)\end{array}$ \\
\hline $4(>14)$ & $\begin{array}{l}3.44(2.50- \\
4.70)\end{array}$ & $\begin{array}{l}3.12(1.25- \\
4.41)\end{array}$ & $\begin{array}{l}3.01(1.05- \\
4.81)\end{array}$ & $\begin{array}{l}2.91(1.05- \\
4.81)\end{array}$ \\
\hline P for trend & $<0.001$ & $<0.001$ & 0.001 & 0.009 \\
\hline
\end{tabular}

OR: odds ratio; CI: confidence interval; HR: hazard ratio.

*Model 2 for early mortality was adjusted for: age; BMI $<18.5$ and $>30 \mathrm{~kg} / \mathrm{m}^{2}$ glomerular filtration rate; extracardiac arteriopathy; LV function; critical preoperative state.

Model 2 for late mortality was adjusted for age; BMI $<18.5$ and $>30 \mathrm{~kg} / \mathrm{m}^{2}$, glomerular filtration rate; chronic lung disease; diabetes, extracardiac arteriopathy; LV function.

From May 2004 to October 2011 a total of 8340 patients underwent isolated CABG, baseline characteristics stratified by preoperative RDW levels are shown in Table 1. The minimum follow-up for surviving patients was 60 days, with a mean follow-up of $4323 \pm 1497$ days and a median of 4485 days.

The rates of 30 day mortality from the lowest RDW quartile to the highest were $0.6(n=13), 1.4(n=30), 1.9(n=37)$, and $3.5 \%(n=73)$, respectively. Compared with subjects in the lowest RDW quartile in unadjusted models, subjects in the highest RDW quartile had an odds ratio of 3.2 (95\%Cl 2.70-4.10) (for trend across quartiles, $\mathrm{P}<0.001$ ). After adjusting for confounding factors, the correlation remained significant $(\mathrm{P}$ values for trend were $<0.001,0.005$, and 0.009 respectively in Model 2, 3 and 4; Table 2).

The incidence of late death from the lowest RDW quartile to the highest was $0.36,0.49,0.97$, and $1.6 \%$ per 100 patients/year, respectively. Compared with subjects in the lowest RDW quartile in unadjusted models, subjects in the highest RDW quartile had a hazard ratio of 3.4 (95\%CI 2.50-4.70; for trend across quartiles, $\mathrm{P}<0.001$ ). The correlation remained significant also in Models 2, 3, and 4: P values for trend were $<0.001,0.001$, and 0.009; respectively (Table 2).

Kaplan-Meier analysis showed a significant decrease in survival probability among RDW quartiles (log-rank test $\mathrm{P}<0.001$; Fig. 1). Focusing on cardiac-related mortality a significant trend towards increased mortality among RDW quartiles was confirmed (HR 1.7; 95\%CI: 1.1-2.7; $\mathrm{P}=0.02$ ).

Anaemia was defined as haemoglobin $<13 \mathrm{~g} / \mathrm{dL}$ in men and $<12 \mathrm{~g} /$ $\mathrm{dL}$ in women, as defined by the World Health Organization; patients with RDW values $>75$ th percentile showed significantly increased risk of late death both if anaemic (OR 4.1; 95\%CI 2.4-6.2; $\mathrm{P}=0.001$ ) or not anaemic (OR 2.8; 95\%CI 1.3-4.8; $\mathrm{P}=0.003$ ); whilst anaemic patients with RDW values $\leq 75$ th percentile showed a slightly significant increased risk for late death (OR 3.0; 95\%CI 1.3-5.1; $\mathrm{P}=0.09$ ).

This retrospective analysis showed that RDW, a simple morphologic marker of red blood cell size heterogeneity, is a powerful predictor of early and late death in patients undergoing CABG. We found this association to be independent of multiple potential confounding factors, including anaemia and nutritional factors; and,

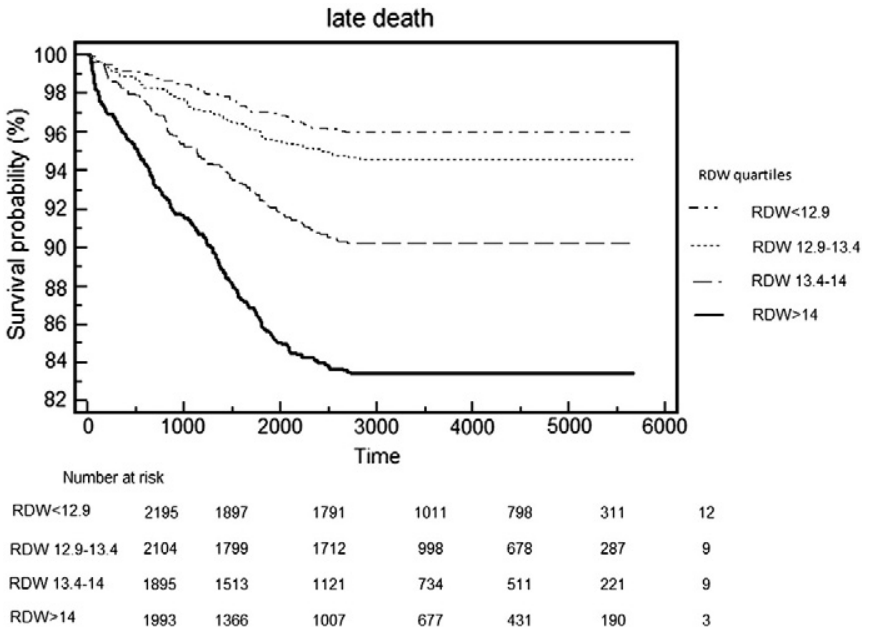

Fig. 1. Kaplan-Meier survival curves according to the preoperative red blood cell distribution width (RDW) quartiles.RDW: range distribution width.

to our knowledge, this is the first study to correlate RDW with a mortality risk of CABG patients. This finding is further strengthened by the evidence that cardiac-related late death as well is associated with RDW quartiles.

Considerable effort has been expended at identifying patients purportedly at greater risk of early and late death after CABG, from our observations, it appears that RDW holds considerable promise as a powerful predictor of early and late death; particularly attractive is that these data are widely available (as a part of the complete blood count) to the clinician at no extra cost.

RDW may be an earlier marker of prognosis than haemoglobin, as it may reflect early steps in the complex processes of anaemia, when ineffective production and increased destruction of red cells are occurring, but haemoglobin is still within the normal range [6].

However, increased RDW could affect outcomes irrespective of anaemia status, maybe because the pathophysiologic mechanism might be due to chronic subclinical inflammation which precedes de novo cardiovascular events [7], and can affect erythropoiesis by means of direct myelo-suppression of erythroid precursors, reduced renal erythropoietin production and bioavailability of iron, increased erythropoietin resistance in erythroid precursor cell lines, and promoted cell apoptosis [8]. Thus, inflammation could lead to anisocytosis because of the release of immature red blood cells into the peripheral circulation.

Another evidence supporting the chronic inflammation pathway, is the linearly increased levels of CRP through greater RDW quartiles (Table 1); in addition, a greater oxidative stress might be yet another potential patho-physiologic mechanism leading to atherosclerosis [9].

\section{References}

[1] Ranucci M, Castelvecchio S, Menicanti L, Frigiola A, Pelissero G. Risk of assessing mortality risk in elective cardiac operations. Circulation 2009;119:3053-61.

[2] O'Boyle F, Mediratta N, Fabri B, et al. Long-term survival after coronary artery bypass surgery stratified by EuroSCORE. Eur J Cardiothorac Surg Jan 4 2012;42:101-6.

[3] van Straten AH, Hamad MA, van Zundert AJ, Martens EJ, Schönberger JP, de Wolf AM. Preoperative hemoglobin level as a predictor of survival after coronary artery bypass grafting. Circulation 2009;120:118-25.

[4] Zindrou D, Taylor KM, Bagger JP. Preoperative haemoglobin concentration and mortality rate after coronary artery bypass surgery. Lancet 2002;359:1747-8.

[5] Zalawadiya SK, Veeranna V, Niraj A, Pradhan J, Afonso L. Red cell distribution width and risk of coronary heart disease events. Am J Cardiol 2010;106:988-93.

[6] Tonelli M, Sacks F, Arnold M, Moye L, Davis B, Pfeffer M. Relation between red blood cell distribution width and cardiovascular event rate in people with coronary disease. Circulation 2008;117:163-8.

[7] Okonko DO, Grzeslo A, Witkowski T, et al. Effect of intravenous iron sucrose on exercise tolerance in anemic and nonanemic patients with symptomatic chronic heart failure and iron deficiency FERRIC-HF: a randomized, controlled, observer-blinded trial. J Am Col Cardiol 2008;51:103-12. 
8] Khaw KT, Wareham N, Bingham S, Luben R, Welch A, Day N. Association of hemoglobin A1c with cardiovascular disease and mortality in adults: the European prospective investigation into cancer in Norfolk. Ann Intern Med 2004;141:413-20.
[9] Berliner JA, Navab M, Fogelman AM, et al. Atherosclerosis: basic mechanisms. Oxidation, inflammation, and genetics. Circulation 1995;91:2488-96.

\title{
Implantable defibrillators in cardiac amyloidosis 2 放
}

\author{
Karin P.M. van Galen ${ }^{\mathrm{a}, *}$, Jeroen van Dijk ${ }^{\mathrm{b}}$, Josien C. Regelink ${ }^{\mathrm{c}}$, Peter C. Huijgens ${ }^{\mathrm{c}}$, \\ Monique C. Minnema ${ }^{a}$, Sonja Zweegman ${ }^{\mathrm{c}}$ \\ a Department of Hematology, University Medical Center Utrecht, Heidelberglaan 100, 3508 GA Utrecht, The Netherlands \\ b Department of Cardiology, VU University Medical Center, de Boelelaan 1117, 1081 HV Amsterdam, The Netherlands \\ c Department of Hematology, VU University Medical Center, de Boelelaan 1117, 1081 HV Amsterdam, The Netherlands
}

\section{A R T I C L E I N F O}

\section{Article history:}

Received 1 July 2012

Accepted 23 August 2012

Available online 16 September 2012

Keywords:

Cardiac amyloidosis

Sudden death

Implantable cardioverter-defibrillator

To the Editor,

Light-chain (AL) amyloidosis is a malignant disease caused by a small monoclonal population of plasma cells in the bone marrow. This cell population produces monoclonal immunoglobulin light chains (FLC) that aggregate into amyloid fibrils and cause organ failure due to tissue deposition. In more than half of the cases there is cardiac involvement, by far the most relevant factor for poor prognosis [1]. Historically, median survival for cardiac AL amyloidosis (CA) is less than one year [1]. Two thirds of the CA patients die of cardiac causes and half of them die suddenly [2].

In recent years several effective therapies for AL amyloidosis appeared on the horizon [3]. High dose melphalan followed by rescue with autologous stem-cell transplantation (HDM) is considered to be highly effective for eligible patients, leading to durable remissions and survival [4-6]. Several other effective therapy regimens are valuable alternatives [3]. Current treatment modalities also have the potential of important cardiac responses $[3,7,8]$. Unfortunately, SD interferes with the possibility of a prolonged life span by effective amyloidosis treatment $[9,10]$.

Implantable cardioverter-defibrillators (ICDs) reduce mortality in patients with heart failure (HF) [11]. In CA patients, ICDs could have the potential to prevent SD while awaiting cardiac response from amyloidosis treatment. To answer which CA patients are at risk for tachyarrhythmiaassociated SD and who could benefit from an ICD to prevent SD, we conducted a retrospective monocenter study and literature review.

In our patient registry we identified $24 \mathrm{AL}$ amyloidosis patients between 1999 and 2009, of whom 54\% had cardiac involvement and 2 received an ICD. (Table 1: patients $A$ and $B$ ) Patient $A$, also treated with amiodarone, had an ICD implanted as secondary prophylaxis after VT with a successful ICD discharge and probable survival benefit. He died

\footnotetext{
All authors take responsibility for all aspects of the reliability and freedom from bias of the data presented and their discussed interpretation.

* Corresponding author. Tel.: + 318875572 30; fax: + 31887555438

E-mail address: k.p.m.van.galen@umcutrecht.nl (K.P.M. van Galen).
}

14 months following implantation due to progressive amyloidosis. Patient B had prophylactic ICD implantation because of CA associated HF with a successful discharge 2 years later when a VT occurred during hemodialysis. He died 7 months later, still in remission, due to a non-cardiac cause.

In literature we found 11 publications on CA and ICDs until August 6, 2011, comprising 8 case reports (Table 1). Five of these ICDs successfully aborted potentially fatal tachyarrhythmias with probable survival benefit in 4 patients [12-19]. In 2 studies on 30 patients with advanced CA who had an ICD implanted as secondary prophylaxis after tachyarrhythmic events or syncope, $10 \%$ had successful shocks $[20,21]$. In 11 CA patients treated with chemotherapy, an ICD could not prevent SD in 55\% and median survival was only 3.5 months after implantation. One patient had recurrent successful shocks but finally died of congestive HF. Post-mortem ICD interrogation in 2 patients revealed electromechanical dissociation (EMD) [20]. The second study prospectively followed 19 CA patients with HF. Two patients (12\%) had sustained VTs that were successfully treated by ICD therapy. One of these patients survived for more than 30 months after repeated ICD-aborted VTs, had no more arrhythmic events after amiodarone treatment and achieved $\mathrm{CR}$ of the $\mathrm{AL}$ amyloidosis. However $32 \%$ of these patients died of EMD [21]. The authors concluded that ICD implantation is ineffective in preventing SD in these CA patients [20,21].

It is clear from this case series that it is important to predict who will benefit from an ICD. Congestive HF, occurring in approximately $70 \%$ of CA patients, is not predictive of SD in CA [2]. In view of the benefits of ICDs in lower risk patients with HF it would be interesting to know whether ICD implantation will be more efficacious in earlier stages of CA, however this has not been studied [22]. Cardiology guidelines published in 2006 do not recommend ICD devices in CA patients because of poor survival rates [23]. However, it is important to realize that new treatment options that became available after 2006, such as bortezomib, have shown high response rates with a remarkable rapidity of action and limited cardiac toxicity $[3,24]$.

It is doubtful if Holter recordings are sensitive enough to predict benefit from ICDs. Although tachyarrhythmic events appear in 25-57\% of CA patients $[2,25]$ and the presence of couplets was found to predict SD in $51 \mathrm{AL}$ amyloidosis patients [25], SD occurred in a similar proportion of patients with and without VT on 24-h Holter recordings [2].

Continuous telemetric monitoring detected arrhythmias in all CA patients $(\mathrm{n}=24)$ during HDM treatment, most common nonsustained VT's, and altered management decisions in $83 \%$, including ICD placement in $4 \%$. However, 2 patients died despite prompt resuscitation efforts indicating that the potential value of prophylactic ICD therapy remains to be demonstrated [26]. 